\author{
Anna W. Sobańska, Paulina Jakubczyk, Jarosław Pyzowski, Elżbieta Brzezińska \\ Department of Analytical Chemistry, Faculty of Pharmacy, Medical University of Lodz \\ ul. Muszyńskiego 1, 90-151 Lodz, Poland, anna.sobanska@umed.lodz.pl
}

\title{
QUANTIFICATION OF SYNTHETIC FOOD DYES IN BEVERAGES OR PHARMACEUTICAL TABLETS BY SOLID PHASE EXTRACTION (SPE) FOLLOWED BY UV/VIS SPECTROPHOTOMETRY
}

\begin{abstract}
Synthetic food dyes (E102, E104, E110, E122, E124, E132, E133) were concentrated by solid phase extraction on aminopropyl modified silica with aqueous sodium hydroxide or selected amines as eluents. Ponceau 4R (E124) was used as the model dye in the studies of the elution step. The recoveries of E124 differed depending on the eluent and ranged from 76\% (AMP) to over 90\% (TEA, imidazole, $\mathrm{NaOH}$ ). Diluted aqueous triethanolamine (TEA) was found to be a suitable eluent for E124 but other dyes were eluted more effectively with $\mathrm{NaOH}$. The solid extraction process was combined with UV/VIS spectroscopy to quantify synthetic dyes in drinks and OTC pharmaceutical tablets. The SPE-UV/VIS spectroscopic method was validated in terms of linearity, accuracy (recovery of dyes from spiked preparations), precision (repeatability, intermediate precision) and limits of detection/quantification. The method was found sufficiently fast, easy and reliable for the routine control of dyes in these types of products.
\end{abstract}

\section{Keywords}

Food dyes, quantification, SPE, VIS spectrophotometry.

\section{Introduction}

Color is an important feature of food, often associated with its quality, taste, and flavor. Because the majority of foods consumed nowadays are processed, much of what we eat would not look good if it was not colored. Synthetic food dyes are frequently used for this purpose because they can be mass-produced at a fraction of the cost of manufacturing natural food colorings, their shelf life is longer than that of natural dyes and the variety of colors that can be artificially produced in a lab is almost unlimited.

Despite increasing awareness of their potential harmfulness, synthetic food dyes are commonly used in foods, beverages, pharmaceutical preparations and dietary supplements [1]. Analytical techniques used for their quantification in various matrices include chromatography (thin layer chromatography [2-5], reversed-phase [2, 6-9] or ion-pair [2, 9-12] liquid chromatography), electrochromatographic techniques (capillary electrophoresis [12-18], micellar electrokinetic chromatography $[19,20]$ or microemulsion electrokinetic chromatography [21]), UV/VIS spectroscopy [22-26] voltammetry [27-29] or polarography [30]. Prior to further analysis sample pretreatment is usually needed. Dyes are often isolated by separation techniques such as ion-pair extraction $[24,31]$ or solid phase extraction (SPE) $[3,4,6,7,11,26,32,33]$. The sorbent most commonly used for SPE of synthetic dyes is RP-18 [3,7,11], but other supports such as cotton [6], Amberlite XAD-2 [7], polyurethane foam [26], polyamide [7], N-vinylpyrrolidone and divinylbenzene copolymer [32], neutral primary amine modified divinyl benzene polymer [33] or amino-modified silica [4] have also been used.

The purpose of this study was to develop a simple and cost-effective method of determination of synthetic food dyes in beverages or pharmaceuticals by solid phase extraction combined with VIS spectrophotometry.

\section{Experimental part}

Instrumentation

SPE extraction was performed with the 12 position SPE manifold system purchased from Bioanalytic, Poland, connected to a water vacuum pump and equipped with Cronus SPE aminopropyl columns (200 mg/3 ml). Lambda 25 UV/VIS spectrophotometer from Perkin-Elmer was equipped with $10.02 \mathrm{~mm}$ quartz cuvettes from Kuvette, Marco Roth Karlsruhe, Germany. 


\section{Solvents, chemicals, dye standards}

Methanol and sodium hydroxide were from Chempur, Poland. Morpholine, triethanolamine (TEA), imidazole and 2-amine-2-methyl-1-propanol (AMP) were purchased from Sigma-Aldrich. All solvents and chemicals were of analytical grade. Dyes used as standards were from Food Colours, Poland. Their purity was determined by UV/VIS spectrophotometry according to Ref. [34]. The following synthetic dyes were investigated: quinoline yellow (E104), tartrazine (E102), indigocarmine (E132), brilliant blue (E133), ponceau 4R (E124), orange yellow $\mathrm{S}$ (E110), azorubine (E122).

\section{Solutions}

Solutions of bases ( 0.1 and $0.01 \mathrm{~mol} \mathrm{~L}^{-1} \mathrm{NaOH}, 0.1 \mathrm{~mol} \mathrm{~L}^{-1} \mathrm{AMP}, 0.1$ and $1.0 \mathrm{~mol} \mathrm{~L}^{-1}$ imidazole, 0.1 and $0.01 \mathrm{~mol}$ $\mathrm{L}^{-1}$ trietanolamine, 0.1 and $1.0 \mathrm{~mol} \mathrm{~L}^{-1}$ morpholine) were prepared in distilled water. Dye standard solutions used to generate calibration curves were prepared at concentrations 4, 8, 12, 15, 20 and $25 \mu \mathrm{gL} \mathrm{L}^{-1}$ in distilled water or in solutions of appropriate bases as listed above.

\section{Commercial preparations}

Commercial preparations analyzed throughout this study included:

- Over-the-counter sore throat tablets containing 2,4-dichlorobenzyl alcohol, amylmetacresol, levomenthol, peppermint essential oil, star anise essential oil, sucrose, glucose syrup, tartaric acid and ponceau 4R (E124)

- Fizzy drink containing water, carbon dioxide, sucrose, aspartame, citric acid, modified starch, ester gum (E445), sodium benzoate, grapefruit flavor, azorubine (E122)

- Isotonic drink containing water, dextrose, maltodextrose, citric acid, sodium chloride, potassium citrate, magnesium chloride, calcium chloride, potassium phosphate, strawberry and tropical fruit flavor, acacia gum (E414), ester gum (E445), acesulfam-K, sucralose, brilliant blue (E133).

\section{Lab-prepared preparation}

Samples of an un-colored, commercially available fizzy drink containing water, carbon dioxide, sucrose, aspartame, citric acid, modified starch, ester gum (E445), sodium benzoate and flavor were spiked with the following dyes: E110, E104, E102, E132 at concentrations given in Table 5.

\section{Preparation of samples for SPE extraction}

Aqueous solutions of Ponceau 4R used for SPE optimization were prepared at $0.2 \mu \mathrm{g} \mathrm{mL}^{-1}$ concentrations. Fizzy drinks samples $(5 \mathrm{~mL}$ ) were transferred to $50 \mathrm{~mL}$ volumetric flasks, degassed with ultrasounds and diluted to volume. Pharmaceutical tablets ( $5 \mathrm{pcs}$ ) were dissolved in distilled water $(250 \mathrm{~mL})$ at room temperature and 50 $\mathrm{mL}$ samples of this solution (corresponding to one tablet) were subjected to SPE extraction.

\section{SPE extraction}

SPE aminopropyl columns were conditioned with $2 \times 3 \mathrm{~mL}$ methanol and not allowed to dry. Samples prepared according to the section "Preparation of samples for SPE" were passed through columns at ca. $2 \mathrm{~mL} \mathrm{~min}^{-1} \mathrm{flow}$ rate. Sorbents containing adsorbed dyes were washed with distilled water $(c a .10 \mathrm{~mL})$ to remove impurities. Adsorbed dyes were eluted with aqueous solutions of $\mathrm{NaOH}$, TEA, imidazole, AMP or morpholine prepared according to the section "Solutions". The resulting solutions of desorbed dyes were collected in pre-weighed vials (for aqueous solutions of dyes) or in volumetric flasks (in the case of drinks or tablet samples). Samples collected in vials were weighted immediately after the collection to calculate their weight and volume; samples in volumetric flasks were diluted to volume with an appropriate eluent.

\section{UV/VIS spectroscopy}

The absorption spectra of dye standards and dyes isolated from samples via SPE were recorded between 350 and $650 \mathrm{~nm}$. The selected spectra of dyes $\left(20 \mu \mathrm{g} \mathrm{mL}^{-1}\right.$ in $\left.0.01 \mathrm{M} \mathrm{NaOH}\right)$ are presented in Figure 1. The analytical wavelengths used in spectrophotometric determinations were: E102 - 399 nm; E104 - 383 nm; E110 - 449 nm; E122 - 506 nm; E124 - 506 nm; E133 - 630 nm; E132 - $610 \mathrm{~nm}$. 


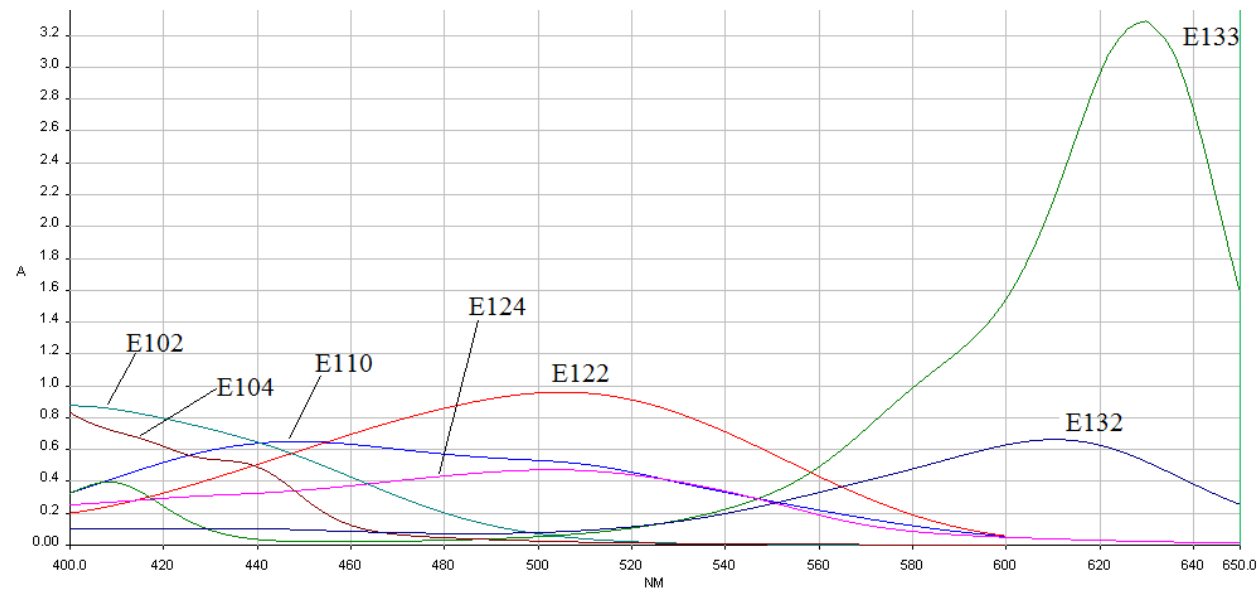

Fig. 1. Spectra of food dyes $\left(20 \mu \mathrm{gL}^{-1}\right.$ in $\left.0.01 \mathrm{M} \mathrm{NaOH}\right)$ Source: Author's

\section{Results and discussion}

\section{SPE procedure optimization}

Synthetic food dyes investigated throughout this study are commonly used in drinks, confectionery, dairy products, pharmaceuticals (e.g. tablets), oral care preparations (toothpastes and mouthwashes) and gelatin desserts. According to some studies their quantification does not require any sample pretreatment apart from dilution and filtration [22,23], but in the majority of cases dyes are isolated and purified by extraction prior to actual determination. From the chemical point of view many synthetic food dyes (including the compounds analyzed in this study) are strong organic acids (neutralized with suitable bases) and their acidic-basic properties make them suitable objects for procedures such as ion-pair solvent extraction or ion-pair chromatography. It seemed therefore reasonable to isolate them by solid phase extraction in the ion exchange mode. Such an approach has been seldom applied so far. In the majority of published studies synthetic dyes are subjected to SPE on C18, Amberlite XAD-2, polyamide or polyamide foam $[3,6,7,11,26,32,33]$ - supports dedicated primarily to separation of neutral molecules of different polarity and size. Anions of carboxylic or sulfonic acids can be effectively separated on anion exchange sorbents $[4,7,33,35]$. Retention of an analyte, bearing a negative charge, requires a positively charged anion exchange sorbent to ensure suitable ionic interactions. This can be achieved on strong anion exchangers (SAX), where the sorbent (a silica bonded quaternary ammonium salt) bears a permanent positive charge or on weak anion exchangers (WAX) containing silica bonded neutral $\mathrm{NH}_{2}$ groups that must be ionized during the retention step with the solution of the suitable $\mathrm{pH}$ (at least $2 \mathrm{pH}$ units below the pKa of the sorbent). During the elution step the charge on either the sorbent or the analyte must be neutralized to break the ionic interactions that make the analyte bind to the sorbent. In the case of food dyes analyzed in the course of this study weak anion exchangers are more suitable since anions of very strong acids such as sulfonic acids may retain irreversibly on strong anion exchangers [35]. In previously published papers on isolation of synthetic food dyes on WAX type sorbents both strategies of elution were presented and the solutions used as eluents were either acidic (to neutralize the positive charge on the sorbent) or basic (to neutralize the negative charge on the analyte), respectively [4,33]. After the SPE extraction chromatographic (TLC [4] or UPLC [33]) determination of isolated dyes followed.

We have decided that prior to the spectrophotometric determination the synthetic dyes analyzed in this study should be isolated by solid phase extraction on the WAX type aminopropyl sorbent with basic rather than acidic elution. This step can be achieved with aqueous sodium hydroxide [35] or methanolic ammonia [33] but such conditions are not particularly mild. In the course of this study the solutions of selected organic bases (morpholine, imidazole, triethanolamine, aminopropylmethanol) were tested in search for mild yet effective conditions. The optimization of the elution step was carried out using ponceau 4R (E124, $40 \mu \mathrm{g}$ in $200 \mathrm{ml}$ water) as a model dye. The recoveries of this dye obtained by different basic eluents given in Table 1 were determined spectrophotometrically on the basis of calibration plots generated for E124 in the solutions of appropriate bases (Table 2). After the analysis of these recoveries the least effective of all organic bases (AMP, morpholine) were excluded from further studies. The effectiveness of imidazole solutions as eluents was also considered unsatisfactory since to achieve the reasonable rate of elution relatively high concentrations (compared to TEA) of this base were needed. 
Table 1. Recoveries of E124 after SPE with different eluents. Volumes of solutions after the elution step were determined by weight. Standard solutions used to generate calibration plots were prepared in appropriate media as described above ("Solutions").

\begin{tabular}{|l|l|l|l|l|}
\hline Eluent & Volume after elution $[\mathrm{ml}]$ & Dye concentration $\left[\boldsymbol{\mu g} \mathbf{~ m L}^{-1}\right.$ ] & Dye weight $[\boldsymbol{\mu g}]$ & Recovery [\%] \\
\hline TEA 0.1 M & 1.39 & 26.6 & 37.0 & 92.5 \\
\hline TEA 0.01 M & 2.83 & 13.0 & 36.9 & 92.2 \\
\hline imidazole 1 M & 1.36 & 27.5 & 37.4 & 93.6 \\
\hline imidazole 0.1 M & 4.47 & 8.3 & 37.2 & 93.0 \\
\hline morpholine 1 M & 1.25 & 24.2 & 30.3 & 75.8 \\
\hline morpholine 0.1 M & 1.30 & 25.5 & 33.2 & 83.0 \\
\hline AMP 0.1 M & 1.19 & 25.6 & 30.5 & 76.2 \\
\hline $\mathrm{NaOH} \mathrm{0.01} \mathrm{M}$ & 2.27 & 16.4 & 37.3 & 93.3 \\
\hline
\end{tabular}

Source: Author's

Table 2. Calibration plots for Ponceau 4R (E124) in different media

\begin{tabular}{|c|c|c|c|c|c|c|c|}
\hline & $\begin{array}{l}\text { Imidazole } \\
0.1 \mathrm{M}\end{array}$ & $\begin{array}{l}\text { Imidazole } \\
1 \mathrm{M}\end{array}$ & $\begin{array}{l}\text { Morpholine } \\
0.1 \mathrm{M}\end{array}$ & $\begin{array}{l}\text { Morpholine } \\
\text { 1M }\end{array}$ & $\begin{array}{l}\text { TEA } \\
0.01 \mathrm{M}\end{array}$ & TEA 0.1M & $\begin{array}{l}\mathrm{NaOH} \\
0.01 \mathrm{M}\end{array}$ \\
\hline a (slope) & 0.043 & 0.043 & 0.042 & 0.040 & 0.043 & 0.042 & 0.025 \\
\hline $\mathrm{b}$ (intercept) & 0.004 & 0.0065 & 0.0047 & 0.0053 & 0.0079 & 0.0037 & -0.009 \\
\hline $\mathrm{S}_{\mathrm{a}}$ & 0.00025 & 0.00018 & 0.00027 & 0.00010 & 0.00022 & 0.00022 & 0.00050 \\
\hline$S_{b}$ & 0.0038 & 0.0027 & 0.0040 & 0.0015 & 0.0033 & 0.0033 & 0.0075 \\
\hline $\mathrm{R}^{2}$ & 0.9999 & 0.9999 & 0.9999 & 0.9999 & 0.9999 & 0.9999 & 0.9985 \\
\hline$S_{x y}$ & 0.0041 & 0.0029 & 0.0043 & 0.0017 & 0.0036 & 0.0035 & 0.0081 \\
\hline LOD/LOQ [ $\left.\mu \mathrm{g} \mathrm{mL}^{-1}\right]$ & $0.29 / 0.87$ & $0.21 / 0.63$ & $0.31 / 0.93$ & $0.12 / 0.36$ & $0.25 / 0.75$ & $0.26 / 0.78$ & $0.99 / 2.97$ \\
\hline $\begin{array}{ll}\text { Linearity } & \text { range } \\
{\left[\mu \mathrm{gL} \mathrm{m}^{-1}\right]} & \end{array}$ & $0-30$ & $0-30$ & $0-30$ & $0-30$ & $0-30$ & $0-30$ & $0-30$ \\
\hline
\end{tabular}

Source: Author's

Spectrophotometric calibration in selected media

Further SPE experiments involved elution with either $\mathrm{NaOH}$ or TEA. It was established that synthetic dyes differ significantly in terms of their affinity to the aminopropyl sorbent. Elution with diluted aqueous organic amines is possible in all cases, but the necessary amount of the eluent is different for different dyes so in most cases (E122, E133, E110, E104, E102, E132) aqueous $\mathrm{NaOH}$ was preferred to keep the eluent volume within reasonable limits. $0.01 \mathrm{M} \mathrm{NaOH}$ was effective for all dyes but further reduction of the eluent volume was possible with $\mathrm{NaOH}$ at higher concentrations (e.g. 0.1M). Parameters of calibration plots generated for different synthetic dyes in $0.01 \mathrm{M} \mathrm{NaOH}$ are presented in Table 3 and for E122 and E133 in $0.1 \mathrm{M} \mathrm{NaOH}$ in Table 4.

Table 3. Parameters of calibration plots of different dyes in $0.01 \mathrm{M} \mathrm{NaOH}$

\begin{tabular}{|l|l|l|l|l|l|l|l|}
\hline & E122 & E110 & E104 & E102 & E124 & E133 & E132 \\
\hline $\mathrm{a}$ (slope) & 0.045 & 0.029 & 0.053 & 0.040 & 0.025 & 0.162 & 0.037 \\
\hline $\mathrm{b}$ (intercept) & 0.016 & 0.011 & 0.017 & 0.014 & -0.017 & 0.099 & -0.012 \\
\hline $\mathrm{S}_{\mathrm{a}}$ & 0.00046 & 0.00036 & 0.00052 & 0.00042 & 0.0005 & 0.003 & 0.00042 \\
\hline $\mathrm{S}_{\mathrm{b}}$ & 0.0074 & 0.0060 & 0.0078 & 0.0071 & 0.0075 & 0.04 & 0.0060 \\
\hline $\mathrm{R}^{2}$ & 0.9996 & 0.9994 & 0.9996 & 0.9996 & 0.9985 & 0.9989 & 0.9995 \\
\hline $\mathrm{S}_{\mathrm{xy}}$ & 0.0081 & 0.0065 & 0.0084 & 0.0076 & 0.0081 & 0.038 & 0.0065 \\
\hline LOD/LOQ $\left[\mu \mathrm{g} \mathrm{mL}^{-1}\right]$ & $0.54 / 1.62$ & $0.68 / 2.04$ & $0.49 / 1.47$ & $0.59 / 1.77$ & $0.99 / 2.97$ & $0.81 / 2.43$ & $0.53 / 1.59$ \\
\hline Linearity range $\left[\mathrm{\mu g} \mathrm{mL}^{-1}\right]$ & $0-30$ & $0-30$ & $0-30$ & $0-30$ & $0-30$ & $0-20$ & $0-30$ \\
\hline
\end{tabular}

Source: Author's 
Table 4. Parameters of calibration plots in $0.1 \mathrm{M} \mathrm{NaOH}$

\begin{tabular}{|c|c|c|}
\hline & E122 & E133 \\
\hline $\mathrm{a}$ (slope) & 0.045 & 0.155 \\
\hline $\mathrm{b}$ (intercept) & 0.0079 & 0.093 \\
\hline $\mathrm{S}_{\mathrm{a}}$ & 0.00023 & 0.0032 \\
\hline $\mathrm{S}_{\mathrm{b}}$ & 0.0036 & 0.042 \\
\hline $\mathrm{R}^{2}$ & 0.9999 & 0.9987 \\
\hline $\mathrm{S}_{\mathrm{xy}}$ & 0.0039 & 0.040 \\
\hline $\mathrm{LOD}\left[\mu \mathrm{gL}^{-1}\right]$ & 0.26 & 0.89 \\
\hline LOQ $\left[\mu \mathrm{mL}^{-1}\right]$ & 0.78 & 2.67 \\
\hline Linearity range $\left[\mu \mathrm{gL}^{-1}\right]$ & $0-30$ & $0-20$ \\
\hline
\end{tabular}

Source: Author's

Table 5. Recoveries of dyes - pure ${ }^{\mathrm{a}}$ and spiked ${ }^{\mathrm{b}}$ products

\begin{tabular}{|c|c|c|c|c|}
\hline Product & Dye & $\begin{array}{l}\text { Mean determined dye content } \\
{\left[\mu \mathrm{g} \mathrm{mL}^{-1} \text { of drink] }\right.} \\
{[\mu \mathrm{g} \text { per tablet], } \mathrm{n}=3} \\
(\mathrm{SD}[\%])\end{array}$ & 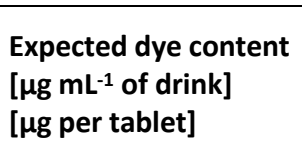 & $\begin{array}{l}\text { Recovery } \\
{[\%]}\end{array}$ \\
\hline \multirow{3}{*}{ Pink drink } & \multirow{3}{*}{$\begin{array}{l}\text { Azorubine } \\
\text { E122 }\end{array}$} & $13.9^{a}(5.9)$ & - & - \\
\hline & & $29.5^{b}(7.8)$ & 30.5 & 96.7 \\
\hline & & $47.3^{\mathrm{b}}(6.5)$ & 47.1 & 100.4 \\
\hline \multirow{3}{*}{ Blue drink } & \multirow{3}{*}{$\begin{array}{l}\text { Brilliant blue } \\
\text { E133 }\end{array}$} & $3.4^{\mathrm{a}}(5.6)$ & - & - \\
\hline & & $8.0^{\mathrm{b}}(5.1)$ & 7.4 & 108.0 \\
\hline & & $11.8^{b}(7.0)$ & 11.4 & 103.5 \\
\hline \multirow{3}{*}{ Red tablet } & \multirow{3}{*}{$\begin{array}{l}\text { Ponceau 4R } \\
\text { E124 }\end{array}$} & $335.0^{\mathrm{a}}(4.0)$ & - & - \\
\hline & & $416.6^{\mathrm{b}}(4.6)$ & 412.0 & 101.1 \\
\hline & & $474.3^{b}(6.2)$ & 489.0 & 97.0 \\
\hline \multirow{12}{*}{$\begin{array}{l}\text { Lab-prepared } \\
\text { fizzy drinks }\end{array}$} & \multirow{3}{*}{ Orange yellow E110 } & $9.1(6.8)$ & 10.0 & 91.0 \\
\hline & & $27.3(8.1)$ & 30.0 & 91.0 \\
\hline & & 47.5 (7.3) & 50.0 & 95.0 \\
\hline & \multirow{3}{*}{$\begin{array}{l}\text { Quinoline yellow } \\
\text { E104 }\end{array}$} & $9.5(4.9)$ & 10.0 & 95.0 \\
\hline & & $29.1(5.3)$ & 30.0 & 97.0 \\
\hline & & $48.6(9.1)$ & 50.0 & 97.1 \\
\hline & \multirow{3}{*}{ Tartrazine E102 } & $10.3(5.8)$ & 10.0 & 103.0 \\
\hline & & $31.0(3.7)$ & 30.0 & 103.3 \\
\hline & & $50.1(6.3)$ & 50.0 & 100.0 \\
\hline & \multirow{3}{*}{$\begin{array}{l}\text { Indygo Carmine } \\
\text { E132 }\end{array}$} & $9.4(6.5)$ & 10.0 & 94.0 \\
\hline & & 28.8 (4.9) & 30.0 & 96.0 \\
\hline & & 48.9 (5.4) & 50.0 & 97.8 \\
\hline
\end{tabular}

Source: Author's

Table 6. Repeatability and intermediate precision of dyes determinations

\begin{tabular}{|c|c|c|c|c|}
\hline \multirow{2}{*}{ Product } & \multirow{2}{*}{ Dye } & \multicolumn{3}{|c|}{$\begin{array}{l}\text { Determined dye content } \\
\text { [ } \mu \mathrm{g} \mathrm{mL}^{-1} \text { of drink], [ } \mu \mathrm{g} \text { per tablet] }\end{array}$} \\
\hline & & Day I, Analyst A & Day I, Analyst B & Day II \\
\hline Pink drink & Azorubine E122 & 13.9 & 13.8 & 14.0 \\
\hline Blue drink & Brilliant blue E133 & 3.4 & 3.5 & 3.3 \\
\hline Red tablet & Ponceau 4R E124 & 335.0 & 338.0 & 335.0 \\
\hline \multirow{4}{*}{$\begin{array}{l}\text { Lab-prepared } \\
\text { fizzy drinks }\end{array}$} & Orange yellow E110 & 9.1 & 8.9 & 9.1 \\
\hline & Quinoline yellow E104 & 9.5 & 9.4 & 9.4 \\
\hline & Tartrazine E102 & 10.3 & 10.2 & 9.8 \\
\hline & Indigo Carmine E132 & 9.4 & 9.3 & 9.5 \\
\hline
\end{tabular}

Source: Author's 


\section{Determination of synthetic dyes in selected commercial preparations}

Samples of beverages and tablets colored with food dyes under investigation were prepared according to the section "Preparation of samples for SPE". Elution of E122 and E133 was achieved according to the section "SPE extraction" with 0.1M NaOH, E110, E104, E102 and E132 with 0.01M NaOH and E124 with 0.01M TEA and the concentrations of dyes in the resulting solutions were determined spectrophotometrically according to the section "UV/VIS Spectroscopy" (Table 5).

\section{Procedure validation}

To estimate the accuracy of the proposed procedure samples of drinks and tablets analyzed during these investigations were spiked with appropriate dyes and subjected to SPE extraction followed by spectrophotometry. The expected dye contents, results of experimental determinations and recoveries are presented in Table 5. The method precision was also evaluated - the repeatability was tested according to [36] by replicating the entire method on the same day, using the same products, batches of solvents and SPE columns, by the same analyst (Day I, Analysis A and B). Intermediate precision was verified according to [36] by repeating the procedure on the same products but on a different day, by a different analyst, using other batches of solvents and SPE columns (Day II). The results of these experiments presented in Table 6 prove that the method accuracy and precision are sufficient for determination of selected food dyes in beverages and pharmaceutical tablets.

Limits of detection and quantification of the spectrophotometric determinations were estimated on the basis of the parameters of the calibration curves according to the formulas: $L O D=3.3^{*} s_{b} / a$ and $L O Q=3 * L O D$, where $a$ is a slope and $s_{b}-$ a standard deviation of the intercept, respectively (Ref. [36]).

\section{Conclusions}

Synthetic food dyes may be effectively quantified in beverages and pharmaceutical tablets by VIS spectroscopy after isolation by SPE extraction on the aminopropyl sorbent. The elution of the dyes from the sorbent can be achieved with aqueous $\mathrm{NaOH}$ or diluted amines. The calibration plots of Ponceau 4R (E124) used as the model dye differ significantly in terms of slope depending on the eluent - the sensitivity is better when TEA is used instead of $\mathrm{NaOH}$. Other dyes, however, e.g. brilliant blue (E133) or azorubine (E122) are eluted faster with aqueous $\mathrm{NaOH}$ than with amines so for the elution of these colorants $\mathrm{NaOH}$ is the reagent of choice. Substances present in drinks and tablets (actives, sweeteners, flavors) do not interfere.

\section{Acknowledgements}

This research was supported by an internal grant of the Medical University of Lodz, Poland, no. 503/3-01603/503-31-001.The authors declare that there is no conflict of interest regarding the publication of this manuscript.

\section{References}

[1] C. Sociaciu (Ed.), Food colorants. Chemical and Functional Properties, Tylor and Francis 2008, 533-547.

[2] M. Kucharska, J. Grabka, A review on chromatographic methods for determination of synthetic food dyes, Talanta 80 (2010) 1045-1051.

[3] T. Tuzimski T, Determination of Sulfonated Water-Soluble Azo Dyes in Foods by SPE Coupled with HPTLCDAD, J. Planar Chromatogr. 24 (2010) 281-289.

[4] A.M. Anderton, C.D. Incarvito, J. Sherma, Determination of natural and synthetic colors in alcoholic and non-alcoholic beverages by quantitative HPTLC, J. Liq. Chromatogr. Rel. Techn. 20 (1996) 101-110.

[5] F. Soponar, A. Catalin Mot, C. Sarbu, Quantitative determination of some food dyes using digital processing of images obtained by thin-layer chromatography, J. Chromatogr. A 1188 (2008) 295-300. 
[6] M. Gonzalez, M. Gallego, M. Valcarcel, Liquid Chromatographic Determination of Natural and Synthetic Colorants in Liophilized Foods Using an Automatic Solid-Phase Extraction System, J. Agric. Food Chem. 51 (2003) 2121-2129.

[7] J. Kirschbaum, C. Krause, H. Bruckner, Liquid chromatographic quantification of synthetic colorants in fish roe and caviar, Eur. Food. Res. Technol. 222 (2006) 572-579.

[8] J. Kirschbaum et al, Development and evaluation of an HPLC-DAD method for determination of synthetic food colorants, Chromatographia 57 (2003) S115-S119.

[9] M.G. Kiseleva, V.V. Pimenova, K.I. Eller, Optimization of conditions for the HPLC determination of synthetic dyes in food, J. Anal. Chem. 58 (2003) 766-772.

[10] M.C. Gennaro, E. Gioannini, S. Angelino, R. Aigotti, D. Giacosa, Identification and determination of red dyes in confectionery and determination by ion-interaction HPLC, J. Chromatogr. A 767 (1997) 87-92.

[11] M. Perez-Urquiza, M.D.Prat, J.L. Beltran, Determination of sulphonate dyesin water by ion-interaction high-performance liquid chromatography, J. Chromatogr. A 871 (2000) 227-234.

[12] A. DeVilliers, F. Alberts, F. Lynen, A. Crouch, P. Sandra, Evaluation of liquid chromatography and capillary electrophoresis for the elucidation of the artificial colorants brilliant blue and azorubine in red wines, Chromatographia 58 (2003) 393-397.

[13] M.C. Boyce, Determination of additives in food by capillary electrophoresis, Electrophoresis 22 (2001) 1447-1459.

[14] R.A. Frazier, E.L. Inns, N. Dossi, J.M. Ames, H.E. Nursten, Development of a capillary electrophoresis method for the simultaneous analysis of colours, preservatives and sweeteners in soft drinks, J. Chromatogr. A 876 (2000) 213-220.

[15] H.Y. Huang et al., Analysis of food colorants by capillary electrophoresis with large volume sample stacking, J. Chromatogr. A 995 (2003) 29-36.

[16] K.L. Kuo, H.Y. Huang, Y.Z. Hsieh. High-performance capillary electrophoretic analysis of synthetic food colorants, Chromatographia 47 (1998) 249-256.

[17] M. Masar, D. Kaniansky, V. Madajova, Separation of synthetic food colorants by capillary zone electrophoresis in a hydrodynamically closed separation compartment, J. Chromatogr. A 724 (1996) 327336.

[18] J.J. Berzas Nevado, C. Guilberteau Cabanillas, A.M. Contento Salcedo, Anal. Chim. Acta378 (1999) 63-71.

[19] C.O Thompson, V.C. Trenerry, Determination of synthetic colours in confectionery by micellar electrokinetic capillary chromatography, J. Chromatogr. A 704 (1995) 195-201.

[20] S.S. Chou, Y.H. Lin, C.C. Cheng, D.F. Hwang, Determination of synthetic colors in soft drinks and confectioneries by micellar electrokinetic capillary chromatography, J. Food Sci, 67 (2002) 1314-1318.

[21] H.Y. Huang, Determination of food colorants by microemulsion electrokinetic chromatography, Electrophoresis 26 (2005) 867-877.

[22] S. Sayar, Y. Ozdemir, First-derivative spectrophotometric determination of Ponceau 4R, Sunset Yellow and Tartrazine in confectionery products, Food Chem. 61 (1998) 367-372.

[23] S. Sayar, Y. Ozdemir, Determination of Ponceau 4R and Tartrazine in Various Food Samples by Derivative Spectrophotometric Methods, Turk. J. Chem. 21 (1997) 182-187. 
[24] O.W. Lau, M.M.K. Poon, S.C. Mok, F.M.Y. Wong, S.F. Luk, Spectrophotometric determination of single synthetic food colour in soft drinks using ion-pair formation and extraction, Int. J. Food Sci. Technol. 30 (1995) 793-798.

[25] E.C. Vidotti, M.C.E. Rollemberg, Derivative spectrophotometry: a simple strategy for simultaneous determination of food dyes, Quim. Nova 29 (2006) 230-233.

[26] E.C. Vidotti, J.C. Cancino, C.C. Oliveira, M.C.E. Rollemberg. Simultaneous Determination of Food Dyes By First Derivative Spectrophotometry with Sorption onto Polyuretane Foam, Anal. Sci. 21 (2005) 149-153.

[27] Y. Ni, J. Bai, L. Jin, Simultaneous adsorptive voltammetric analysis of mixed colorants by multivariative calibration approach, Anal Chim Acta 329 (1996) 65-72.

[28] Y. Ni, J. Bai, Simultaneous determination of Amaranth and Sunset Yellow by ratio derivative voltammetry, Talanta 44 (1997) 105-109.

[29] J.J.B. Nevado, J.R. Flores, Square wave adsorptive voltammetric determination of sunset yellow, Talanta 44 (1997) 467-474.

[30] S. Combeau, M. Chatelut, O. Vittori. Identification and simultaneous determination of Azorubin, Allura red and Ponceau 4R by differential pulse polarography: application to soft drinks, Talanta 56 (2002) 115-122.

[31] M. Puttemans, L. Dryon, D.L. Massart, Extraction of water-soluble acid dyes by ion-pair formation with trin-octylamine. Anal. Chim. Acta 113 (1980) 307-314.

[32] F. Feng, Y. Zhao, W. Yong, L. Sun, G. Jiang, X. Chu, Highly sensitive and accurate screening of $40 \mathrm{dyes}$ in soft drinks by liquid chromatography-electrospray tandem mass spectrometry, J. Chromatogr. B 879 (2011) 1813-1818.

[33] X. Liu, J.L. Yang, J.H. Li, X.L. Li, J. Li, X.Y. Lu, J.Z. She, Y.W. Wang, Z.H. Zhang, Analysis of water-soluble azo dyes in soft drinks by high resolution UPLC-MS, Food Add. Cont. 28 (2011) 1315-1323.

[34] K.S. Minioti,, C.F. Sakellariou, N.S. Thomaidia, Determination of 13 synthetic food colorants in water soluble foods by reversed - phase high - performance liquid chromatography coupled with diode - array detector, Anal. Chim. Acta 583 (2007) 103-110.

[35] Supelco: Guide to Solid Phase Extraction, Bulletin 910, Internet: http://www.sigmaaldrich.com/Graphics/Supelco/objects/4600/4538.pdf

[36] P. Konieczko, J. Namieśnik, Ocena i kontrola jakości wyników pomiarów analitycznych, Wydawnictwo Naukowo - Techniczne, Warszawa 2007, pp. 52-54, 225-298. 